\title{
O RACISMO, ANTIRRACISMO E BRANQUITUDE: OS SIGNOS E O TEMA EM RESSONÂNCIA DIALÓGICA NO EMBATE IDEOLÓGICO
}

\author{
Camilla Ramos dos Santos \\ Marlúcia Mendes da Rocha ${ }^{* *}$ \\ Isaias Francisco de Carvalho ${ }^{* * *}$
}

A visão de lingua é, portanto, disciplinada por ideologias raciolinguísticas, em que as linguas são vistas como espaços de purificação e limpeza do projeto colonial.

(Gabriel Nascimento)

RESUMO: "Nega maluca", "preto safado", "beiçola" e "cabelo de Bombril" são alguns dos xingamentos dirigidos a pessoas negras. O racismo estrutura e institui o ordenamento das relações étnico-raciais mediante o tema ideológico da branquitude, a partir do contexto colonial até os presentes dias. As ideologias em torno da racialização reverberam sentido como práticas reproduzidas nas condições das relações de produção cultural e impactam de diferentes formas o sistema político que, a priori, exclui afrodescendentes dos espaços de poder e acesso a direitos básicos. Os pares antitéticos na luta inscrita na linguagem em torno do significante "raça" representam discursos disseminados pela transição de uma dinâmica dialética, cuja materialidade interfere também na consciência e no ato de fala de cada indivíduo.

PALAVRAS-CHAVE: Dialética; Filosofia da Linguagem; Relações étnico-raciais.

\section{Introdução}

Já se passaram 132 anos desde a Abolição da Escravatura no Brasil. Quais são as rupturas e continuidades possíveis de imaginar no processo de constituição do corpo afrodescendente, sobretudo nas discussões acerca do racismo e da cidadania? As tradições afrobrasileiras foram incorporadas sem prejuízo ou foram transformadas em fetiche? A mulher negra, ultrassexualizada ao mesmo tempo em que é preterida, possui em seu feminismo as mesmas demandas de uma mulher branca? Por que o homem negro é associado à criminalidade? Para responder a essas perguntas, é necessário tecer reflexões sobre os signos ideológicos racializantes, sobre a branquitude e a negritude, sobre o racismo e o antirracismo. Apesar de "livre" desde o ano 1888, o povo preto precisa se organizar politicamente e culturalmente em seu significado amplo, para reivindicar o seu lugar nessa sociedade que possui uma grande mácula - a negação da cidadania negra.

\footnotetext{
${ }^{*}$ Doutoranda em Letras: Linguagens e Representações pela Universidade Estadual de Santa Cruz (Uesc).

** Doutora em Comunicação e Semiótica pela Pontifícia Universidade Católica de São Paulo (Puc-SP). Professora Titular da Universidade Estadual de Santa Cruz.

*** Doutor em Letras e Lingüística pela Universidade Federal da Bahia (Ufba). Professor da da Universidade Estadual de Santa Cruz.
} 


\section{As ideologias acerca de sintagmas relativos à raça e a branquitude como tema}

Os sintagmas relativos à raça correspondem aos termos "mulher negra/branca", "homem negro/branco", variando, especialmente no Brasil, em "mulata/o", "parda/o", "preta/o", "mestiça/o" e "escurinha/o", entre outros. Designam o status de cada indivíduo e determinam a sua evolução como ente social. Construídos a partir do racismo disseminado pelo ideal da branquitude, justificam e perpetuam a dominação de indivíduos negros por outros considerados superiores quando são brancos. Porém, as injúrias que acompanham os sintagmas relacionados aos afrodescendentes são questionadas, e novas valências semânticas são inscritas na linguagem a partir do empoderamento amparado na luta antirracista. A plurivalência dos sintagmas relacionados à racialização é produzida mediante a conversão em signos, numa dinâmica dialética que envolve a linguagem como um constructo social que flutua entre as ideologias do racismo e do antirracismo.

Segundo Almeida (2019), há uma grande controvérsia sobre a etimologia do termo raça. É possível afirmar que o seu significado sempre esteve ligado ao ato de estabelecer classificações, primeiramente, entre as plantas e os animais e, mais tarde, entre os seres humanos. A sua noção como referência a distintas categorias de seres humanos é um fenômeno da modernidade, que remonta aos meados do século XVI. Raça não é um termo fixo ou estático, e o seu sentido está atrelado às circunstâncias históricas em que é utilizado, envolvendo contingência, conflito, poder e decisão. O filósofo define que a história das raças é a história da constituição política e econômica das sociedades contemporâneas. $\mathrm{O}$ contexto da expansão comercial burguesa e da cultura renascentista ensejou a construção do ideário filosófico moderno que transformou o homem europeu no ser humano universal.

Ainda conforme Almeida (2019), tendo como norte filosófico o pensamento iluminista, o movimento de propagar a civilização redundou num processo de destruição e morte, de espoliação e aviltamento, em nome da razão e a que se denominou colonialismo - o processo de desumanização que antecede as práticas discriminatórias ou os genocídios perpetrados até os presentes dias. O racismo científico obteve enorme repercussão e prestígio nos meios acadêmicos e políticos do século XIX, definindo a raça segundo os registros básicos que se entrecruzam e complementam: a característica biológica e a característica étnico-cultural. Como explica o filósofo, no século XX, parte da antropologia esforçou-se em demonstrar a autonomia das culturas e a inexistência de determinações biológicas ou culturais capazes de hierarquizar a moral, a cultura, a religião e os sistemas políticos, determinando que a raça é um elemento essencialmente político. Apesar disso, a raça ainda se constitui como um fator 
importante para naturalizar as desigualdades e legitimar a segregação e o genocídio de grupos minoritários.

O racismo ${ }^{1}$ diferencia-se de outras categorias que também aparecem associadas à ideia de raça: o preconceito e a discriminação, de acordo com Almeida (2019). O racismo corresponde a uma forma sistemática de discriminação que tem a raça como fundamento, e que se manifesta mediante práticas conscientes ou inconscientes que culminam em desvantagens ou privilégios para indivíduos, de acordo com o grupo racial ao qual pertençam. Também, como explica o filósofo, o racismo articula-se com a segregação racial, ou seja, a divisão espacial de raças em localidades, e/ou à definição de estabelecimentos comerciais e serviços públicos e o atual sistema carcerário. O preconceito racial é o juízo a partir de estereótipos acerca de indivíduos que pertençam a um determinado grupo racializado, podendo ou não resultar em práticas discriminatórias. A discriminação racial, por sua vez, relaciona-se à atribuição de tratamento diferenciado a membros de grupos racialmente identificados, e possui como requisito fundamental o poder. Assim, a discriminação se sustenta na possibilidade efetiva do uso da força, sem o qual não atribuiria vantagens ou desvantagens por conta da raça.

Os exemplos de sintagmas citados são articulados na linguagem como signos ideológicos, possuindo sentidos diferentes a depender do grupo pelo qual são enunciados. Segundo Bakhtin e Volóchinov (1997), ao lado dos fenômenos naturais, do material tecnológico e dos artigos de consumo, há um universo particular, o universo dos signos. Um signo não existe apenas como parte de uma realidade, pois reflete e refrata outra; podendo distorcer essa realidade, ser-lhe fiel, ou apreendê-la de um ponto de vista específico etc. Nesse sentido,

\footnotetext{
Todo signo está sujeito aos critérios de avaliação ideológica (isto é: se é verdadeiro, falso, correto, justificado, bom etc.). O domínio do ideológico coincide com o domínio dos signos: são mutuamente correspondentes. Ali onde o signo se encontra, encontra-se também o ideológico. Tudo que é ideológico possui um valor semiótico. No domínio dos signos, isto é, na esfera ideológica, existem diferenças profundas, pois este domínio é, ao mesmo tempo, o da representação, do símbolo religioso, da fórmula científica e da forma jurídica etc. Cada campo de criatividade ideológica tem seu próprio modo de orientação para a realidade e refrata a realidade à sua própria maneira. Cada campo dispõe de sua própria função no conjunto da vida social. É seu caráter semiótico que coloca todos os fenômenos ideológicos sob a
}

\footnotetext{
1 Almeida (2019) classifica o racismo em três concepções: a) a individualista concebe, de forma limitada, uma espécie de "patologia" ou anormalidade, uma "irracionalidade" a ser combatida no campo jurídico por meio da aplicação de sanções civis ou penais; b) a institucional prevê o resultado do funcionamento das instituições que conferem, ainda que indiretamente, desvantagens e privilégios com base na raça; e c) a estrutural desdobra-se como processo político e histórico. Considera o modo que se constituem as relações políticas, econômicas, jurídicas e até familiares que definem os comportamentos individuais e processos institucionais derivados de uma sociedade cujo racismo é a regra e não a exceção. De forma geral, o filósofo afirma que o racismo fornece o sentido, a lógica e a tecnologia para a reprodução das formas de desigualdade e violência que engendram a vida social contemporânea.
} 
mesma definição geral. (BAKHTIN; VOLÓCHINOV, 1997, p. 32-33, grifos dos autores).

Para esses filósofos, a cadeia de criatividade e de compreensão ideológicas, deslocandose de signo em signo, é única e contínua - um elo de natureza semiótica e, portanto, também de natureza material. Essa cadeia ideológica estende-se de consciência individual em consciência individual, ligando umas às outras, num fenômeno em que os signos emergem do processo de interação. Bakhtin e Volóchinov (1997) defendem que a consciência individual está repleta de signos, alcançando status quando se impregna de conteúdo ideológico/semiótico e, consequentemente, somente no processo de interação social. Também explicam que a realidade dos fenômenos ideológicos é a realidade objetiva dos signos sociais, e as leis dessa realidade são as leis da comunicação semiótica diretamente determinadas pelo conjunto das leis sociais e econômicas. Portanto, a realidade ideológica é uma superestrutura situada acima da base econômica. Separando os fenômenos ideológicos da consciência individual percebese a sua ligação com as condições e às formas da comunicação social, e a natureza do signo nada mais é do que a materialização dessa comunicação. Os filósofos destacam que esse aspecto semiótico e esse papel contínuo da comunicação social como fator condicionante aparecem de maneira clara e completa na linguagem, e a palavra é o fenômeno ideológico por excelência. A realidade toda da palavra é absorvida por sua função de signo, tornando-se o modo mais puro e sensível de relação social.

Nessa perspectiva, a representatividade da palavra, como um fenômeno ideológico, e a nitidez da sua estrutura semiótica servem como razão para colocar a palavra em primeiro plano no estudo das ideologias, pois é precisamente nela que se revelam as formas ideológicas gerais da comunicação semiótica. A palavra não é somente o signo mais puro, mais indicativo; é também um signo neutro. Bakhtin e Volóchinov (1997) descrevem que o signo é criado por uma função ideológica precisa e permanece inseparável dela, mas a palavra, ao contrário, é neutra em relação a qualquer função ideológica específica, pois pode preencher qualquer função, seja ela estética, científica, moral, religiosa etc. Eles expõem que, embora a realidade da palavra, como a de qualquer signo, resulte do consenso entre os indivíduos, uma palavra é, também, produzida pelos próprios meios do organismo individual, o que determina o papel da palavra como material semiótico da vida interior, da consciência, ou aquilo que os filósofos definem como o "discurso interior". Na verdade, a palavra constitui o material flexível e veiculável pelo corpo determinante para que a consciência possa se desenvolver. A palavra constitui um signo social e compreende o instrumento de consciência, acompanhando e 
comentando todo ato ideológico, e nenhum processo de compreensão dos fenômenos ideológicos pode operar sem a participação do discurso interior.

Como explica Almeida (2019), o racismo, enquanto processo político e histórico, se constitui também um processo de construção de subjetividades. Assim, o racismo consegue se perpetuar somente se for capaz de: produzir um sistema de ideias que forneça uma explicação "racional” para a desigualdade racial, e constituir sujeitos cujos sentimentos não sejam profundamente abalados diante da discriminação e da violência racial, considerando "normal" e "natural" que no mundo haja "brancos" e "não brancos".

Segundo Almeida (2019), se por "ideologia” entende-se uma visão falseada, ilusória e fantasiosa da realidade, o problema do racismo como ideologia se conecta com a concepção individualista do racismo. Desse modo, já que o racismo é considerado uma espécie de equívoco, para opor-se a ele bastaria apresentar a verdade do conhecimento filosófico ou científico, cujas conclusões apontam a inexistência de raças e, por consequência, a irracionalidade de todas as teorias e práticas discriminatórias. Entretanto, mais do que a consciência, o racismo como ideologia molda o inconsciente. Assim, a vida cultural e política em que os indivíduos se reconhecem como sujeitos autoconscientes e onde formam os seus afetos é constituída por padrões de clivagem racial inseridos no imaginário e em práticas sociais cotidianas.

As condições estruturais e institucionais racializam os sujeitos, ou seja, o racismo cria a raça e os sujeitos racializados, conforme Almeida (2019). Os privilégios de ser considerado branco não dependem de o indivíduo socialmente branco reconhecer-se ou assumir-se como branco, ou da sua disposição em obter a vantagem que lhe é atribuída pela sua raça. Como o filósofo expõe, o racismo constitui um complexo imaginário social reforçado constantemente pelos meios de comunicação, pela indústria cultural e pelo sistema educacional. Tratase de uma ideologia, considerando que uma ideologia só pode subsistir se estiver ancorada em práticas sociais concretas.

A linguagem é dinâmica e um espelho para as transformações sociais. Em razão do racismo, ser negra/o carrega em si o valor semântico relacionado à sexualidade exagerada, à preguiça, à criminalidade e ao grotesco. A partir dos anos 1970, uma ideologia antirracista que buscava construir a autoestima negra resgatando a sua memória cultural, surgiu no Brasil e no mundo. Não mais embranquecidos e estigmatizados pelo mito da democracia racial, como ocorreu com o samba a partir da política economicista de Getúlio Vargas, as/os afrodescendentes engendraram uma luta por políticas afirmativas e a sua ascensão como produtores da cultura determinando transformações semânticas, ao engendrar o que é conhecido como o "orgulho negro". Como explicam Bakhtin e Volóchinov (1997), as palavras são 
tecidas a partir de inúmeros fios ideológicos e servem de trama a todas as relações sociais em todos os domínios. Definem que a palavra será sempre o indicador mais sensível de todas as transformações sociais, mesmo daquelas que ainda não abriram caminho para sistemas ideológicos estruturados e bem formados.

Conforme Bakhtin e Volóchinov (1997), o ser, no signo, não apenas nele se reflete, mas também se refrata. Isso significa que, no processo da constituição da linguagem, cada ser e grupo também oferece resistência aos processos dominantes da comunicação. O confronto de interesses sociais nos limites de uma só e mesma comunidade semiótica determina essa refração do ser no signo ideológico - a luta de classes. Assim:

Todo signo resulta de um consenso entre indivíduos socialmente organizados no decorrer de um processo de interação, razão pela qual as formas do signo são condicionadas tanto pela organização social de tais indivíduos como pelas condições em que a interação acontece. Uma modificação destas formas ocasiona uma modificação do signo. [...] Realizando-se no processo da relação social, todo signo ideológico, e portanto também o signo linguístico, vê-se marcado pelo horizonte social de uma época e de um grupo social determinados. [...] A cada etapa do desenvolvimento da sociedade, encontram-se grupos de objetos particulares e limitados que se tornam objeto da atenção do corpo social e que, por causa disso, tomam um valor particular. Só este grupo de objetos dará origem a signos, tornar-se-á um elemento da comunicação por signos. (BAKHTIN; VOLÓCHINOV, 1997, p. 44-45, grifos dos autores).

Por esse viés, independentemente da esfera da realidade a qual pertença determinado objeto, para que este entre no horizonte social do grupo e desencadeie uma reação semióticoideológica, é indispensável que ele esteja ligado às condições socioeconômicas essenciais do referido grupo, que concerne de alguma maneira às bases de sua existência material. O objeto necessita adquirir uma significação interindividual, e a partir disso ele poderá ocasionar a formação de um signo, ou seja, entra no domínio da ideologia somente aquilo que adquiriu um valor social. Bakhtin e Volóchinov (1997) demonstram que todos os índices de valor com características ideológicas constituem índices sociais de valor, com pretensões ao consenso social, e apenas em nome desse consenso eles se exteriorizam no material ideológico. Os filósofos denominam a realidade que localiza a formação de um signo como o tema do signo. Cada signo constituído, assim como cada manifestação verbal, possui o seu tema ideológico, possuindo sempre um índice de valor social. Todos os índices sociais de valor dos temas ideológicos chegam igualmente à consciência individual que corresponde a toda ideologia. Tornam-se índices individuais de valor, na medida em que a consciência individual os absorve como sendo seus, mas sua fonte não se encontra na consciência individual. $\mathrm{O}$ índice de valor é por natureza interindividual. Segundo Bakhtin e Volóchinov (1997), o tema e a forma do signo ideológico estão indissoluvelmente ligados, e não podem diferenciar-se a não ser 
abstratamente, pois são as mesmas forças e as mesmas condições que dão vida a ambos. As mesmas condições econômicas que associam um novo elemento da realidade ao horizonte social, que o tornam socialmente pertinente, são as mesmas forças que criam as formas da comunicação ideológica, seja cognitiva, artística, religiosa etc. Essas determinam, por sua vez, as formas da expressão semiótica. Assim, os temas e as formas da criação ideológica constituem as duas facetas de uma só e mesma coisa. O processo de integração da realidade na ideologia, o nascimento dos temas e das formas, se tornam mais facilmente observáveis no plano da palavra.

A institucionalização do ideal da branquitude como um atributo de poder, determinando o homem branco como aquele que domina os diversos grupos excluídos desse padrão, tão racista quanto misógino, funciona como o tema ideológico referente aos signos que orbitam a racialização - um índice valorativo do horizonte social, haja vista a existência do racismo. Como descreve Carreira (2018), a branquitude é diversa, contextual, relacional e caracterizada por inúmeros conflitos, não podendo ser essencializada. A identificação com o padrão normativo dominante - a representação de ser humano universal - consiste na negação de pessoas com qualquer ascendência biológica ou cultural negra; da própria ascendência negra; e da influência da população negra na construção do país.

De acordo com Bento (2002), no Brasil, o branqueamento é considerado como um problema do negro que, descontente e desconfortável com a sua condição, procura identificar-se como branco, miscigenar-se. Nesse processo, o branco pouco aparece, exceto como o modelo universal de humanidade, alvo da inveja e do desejo dos outros grupos raciais e, portanto, desumanizados. Segundo a estudiosa, quando se pesquisa sobre o branqueamento, constata-se que foi um processo inventado e mantido pela elite branca brasileira, que realiza uma apropriação simbólica para fortalecer a autoestima e o autoconceito do grupo branco em detrimento dos demais, legitimando a sua supremacia econômica, política e social. Há também o investimento na construção de um imaginário negativo sobre o negro, que danifica a sua autoestima, culpa-o pela discriminação que sofre e justifica as desigualdades. Conforme Bento (2002), observa-se uma relação dialógica: primeiramente, a estigmatização de um grupo como perdedor e a omissão diante da violência que o atinge; por outro lado, existe o silêncio em torno do grupo que pratica a violência racial e dela se beneficia, concreta ou simbolicamente. O medo e a projeção narcísica estão na gênese de processos de estigmatização de grupos que visam perpetuar as desigualdades e elaborar políticas institucionais de exclusão, chegando ao genocídio. 
Como elementos decisivos para maior politização, entre outros, Carreira (2018) elenca os seguintes: as discussões sobre as ações afirmativas no ensino superior, no mercado de trabalho e nos meios de comunicação; a obrigatoriedade do ensino da História e da Cultura Africana e Afro-brasileira e da educação das relações étnico-raciais em toda a educação básica; a polêmica sobre o racismo presente nas obras do escritor Monteiro Lobato; o aprimoramento da produção de informações e a ampliação de pesquisas sobre as desigualdades raciais; o debate sobre os direitos das comunidades quilombolas; e o protagonismo de coletivos juvenis negros, além do movimento de mulheres negras. Porém, é necessário avançar (ou retomar o avanço em progresso até o golpe civil-midiático de 2016) para marcos normativos e políticas que desconstruam a segregação racial, social, territorial, e fortaleçam a dimensão pública como espaço de todas e todos - por exemplo: prever a obrigatoriedade das ações afirmativas em todo o sistema de ensino. A estudiosa enfatiza que a mobilização não deve servir somente como reparação à população negra, mas como uma condição para o desenvolvimento de uma cultura democrática e a promoção de branquitudes críticas e antirracistas. Não se trata de imputar aos brancos a culpa que imobiliza, mas estimular a responsabilidade dessas pessoas com o desenvolvimento de reflexões íntimas e coletivas, além de ações que possibilitem transformações no enfrentamento do racismo como um sistema que abarca das relações cotidianas às instituições e políticas públicas.

Conforme Bakhtin e Volóchinov (1997, p. 128, grifos dos autores), “um sentido definido e único, uma significação unitária, é uma propriedade que pertence a cada enunciação como um todo." O sentido da enunciação completa é denominado como tema ou unidade temática, e deve ser único. O tema da enunciação é individual e não reiterável, assim como a própria enunciação, e se apresenta como a expressão de uma situação histórica concreta que deu origem à enunciação. Como explicam os filósofos, o tema da enunciação é determinado não só pelas formas linguísticas que entram na composição, como as palavras, as formas morfológicas ou sintáticas e os sons as entoações, mas igualmente pelos elementos não verbais da situação. Através dos elementos da situação, a enunciação é compreendida na forma das suas palavras mais importantes. O tema da enunciação é tão concreto quanto o instante histórico ao qual pertence. De acordo com os filósofos, a enunciação tomada em toda a sua amplitude concreta, como fenômeno histórico, possui um tema, mas além dele, exatamente em seu interior, a enunciação é igualmente dotada de uma significação. Por significação, diferentemente do tema, compreende-se os elementos da enunciação que são reiteráveis e idênticos cada vez que são repetidos. Esses elementos são abstratos e fundados numa convenção, não possuindo existência concreta independente, o que não os impede de formar uma parte 
inalienável e indispensável da enunciação. O tema da enunciação é na essência irredutível a análise, enquanto a significação da enunciação, ao contrário, pode ser analisada em um conjunto de significações ligadas aos elementos linguísticos que a compõem. Ainda, sobre o tema e a significação:

\begin{abstract}
O tema é um sistema de signos dinâmico e complexo, que procura adaptar-se adequadamente às condições de um dado momento da evolução. O tema é uma reação da consciência em devir ao ser em devir. A significação é um aparato técnico para a realização do tema. Bem entendido, é impossível traçar uma fronteira mecânica absoluta entre significação e tema. Não há tema sem significação e vice-versa. Além disso, é impossível designar a significação de uma palavra isolada (por exemplo, no processo de ensinar uma língua estrangeira) sem fazer dela o elemento de um tema, isto é, sem construir uma enunciação, um 'exemplo'. Por outro lado, o tema deve apoiar-se sobre uma certa estabilidade da significação, caso contrário, ele perderia seu elo com o que precede e o que segue, ele perderia em suma, o seu sentido. [...] o tema constitui o estágio superior real da capacidade linguística de significar. De fato, apenas o tema significa de maneira determinada. A significação é o estágio inferior da capacidade de significar. A significação não quer dizer nada em si mesma, ela é apenas um potencial, uma possibilidade de significar no interior de um tema concreto. (BAKHTIN; VOLÓCHINOV, 1997, p. 129-131, grifos dos autores).
\end{abstract}

Nesse excerto, os filósofos explicam que a investigação da significação de elementos linguísticos pode orientar-se para duas direções: para o estágio superior, o tema, de forma que se trataria de uma investigação da significação contextual de uma dada palavra; ou, então, poderia investigar-se o estágio inferior, o da significação, onde seria investigada a significação da palavra no sistema da língua ou, em outros termos, a palavra dicionarizada. Para os filósofos, toda palavra usada na fala real possui não apenas tema e significação no sentido objetivo, de conteúdo, mas também um acento de valor ou apreciativo, ou seja, quando um conteúdo objetivo é expresso pela fala viva, seja dito ou escrito, ele é sempre acompanhado por um acento apreciativo determinado. O mais superficial da apreciação social contida na palavra é transmitido através da entoação expressiva, na maioria dos casos determinada pela situação imediata e frequentemente por suas circunstâncias mais efêmeras. Sem acento apreciativo não há palavra, assim como sem a corrente da comunicação verbal, incluindo o locutor e o receptor, que fornece a luz da significação à palavra. Conforme Bakhtin e Volóchinov (1997), o tema, que é uma propriedade de cada enunciação, realiza-se completa e exclusivamente através da entoação expressiva, sem ajuda da significação das palavras ou da articulação gramatical, quando usamos, por exemplo, uma mesma palavra em situações e entoações diferentes. As entoações podem ser qualificadas como auxiliares marginais das significações linguísticas.

Chamar uma pessoa de negra já não corresponde a uma ofensa, graças à articulação do orgulho racial, à articulação político-cultural, e à ascensão do grupo. Portanto, para 
compreender a dinâmica histórica do tema e das significações se torna indispensável levar em conta a apreciação social. A dinâmica semântica na língua é sempre ligada à transformação do horizonte apreciativo de um dado grupo social, no sentido da totalidade de tudo que tem sentido e importância aos olhos de um determinado grupo, e inteiramente determinada pela expansão da infraestrutura econômica. À medida que a base econômica se expande, ela promove uma real expansão no escopo de existência que é acessível, compreensível e vital para o ser humano:

\begin{abstract}
Os novos aspectos da existência, que foram integrados no círculo do interesse social, que se tornaram objetos da fala e da emoção humana, não coexistem pacificamente com os elementos que se integraram à existência antes deles; pelo contrário, entram em luta com eles, submetem-nos a uma reavaliação, fazem-nos mudar de lugar no interior das unidades do horizonte apreciativo. Essa evolução dialética reflete-se na evolução semântica. Uma nova significação se descobre na antiga e através da antiga, mas a fim de entrar em contradição com ela e de reconstruí-la. O resultado é uma luta incessante dos acentos em cada área semântica da existência. Não há nada na composição do sentido que possa colocar-se acima da evolução, que seja independente do alargamento dialético do horizonte social. A sociedade em transformação alarga-se para integrar o ser em transformação. Nada pode permanecer estável nesse processo. É por isso que a significação, elemento abstrato igual a si mesmo, é absorvida pelo tema, e dilacerada por suas contradições vivas, para retornar enfim sob forma de uma nova significação com uma estabilidade e uma identidade igualmente provisórias. (BAKHTIN; VOLÓCHINOV, 1997, p. 136).
\end{abstract}

O antirracismo contrapõe-se ao ideal da branquitude, correspondendo a um contradiscurso que possui a negritude como a construção simbólica que, então, funciona como um anti-tema, ou um tema ideológico não dominante e que se contrapõe ao tema ideológico "universal". Discute-se a violência perpetrada contra as pessoas negras construindo uma consciência a partir do ideal empoderado baseado na representatividade do povo preto. Como explica Ribeiro (2019), para construir um debate antirracista, é de total importância discutir a branquitude. Como o debate é focado na negritude, pessoas brancas não costumam pensar sobre a sua própria condição. É preciso questionar a ausência de pessoas negras em posição de liderança, uma vez que correspondem a $56 \%$ da população brasileira. Assim, uma pessoa branca deve pensar sobre o lugar que ocupa de modo que compreenda os privilégios que acompanham a sua cor, para que estes não sejam naturalizados ou considerados apenas esforço próprio. Segundo a filósofa, o racismo foi inventado pela branquitude, sendo necessário desnaturalizar o seu olhar, naturalizando práticas antirracistas e criando possibilidades de acesso a espaços de poder para as/os afrodescendentes. 


\section{Vidas negras importam}

De acordo com Ribeiro (2019), desde sua infância, as/os negras/os são obrigadas/os a refletir sobre sua condição racial. $\mathrm{O}$ racismo começa na escola. A violência cotidiana, infelizmente naturalizada, deve passar por uma reflexão sobre a constituição das bases para a constante disseminação do sistema racista. Como relembra a filósofa, as pessoas negras costumam ser reduzidas a determinados estereótipos e a objetos, ao invés de serem reconhecidas como seres humanos em toda a sua complexidade e contradições. Os elogios costumam ser artificiais e condescendentes. Ribeiro (2019) salienta que é inaceitável que um grupo racial domine toda a produção do saber e seja a única referência estética. Como resposta, a população negra criou estratégias ao longo de sua história para superar essa marginalização, com movimentos sociais e nas artes. Os produtos da cultura negra contribuem para o aprendizado acerca da negritude. Em conclusão:

É importante ter em mente que para pensar soluções para uma realidade, devemos tirá-la da invisibilidade. Portanto, frases como 'eu não vejo cor' não ajudam. O problema não é a cor, mas seu uso como justificativa para segregar e oprimir. Vejam cores, somos diversos e não há nada de errado nisso - se vivemos relações raciais, é preciso falar sobre negritude e também sobre branquitude. (RIBEIRO, 2019, p. 30).

Por sua vez, Munanga (2009) advoga que os componentes essenciais na construção de uma identidade ou de uma personalidade coletiva englobam os fatores históricos, psicológicos, linguísticos, culturais, político-ideológicos e raciais. A identidade de um grupo funciona como uma ideologia que permite a seus membros se definirem em contraposição aos membros de outros grupos, com o objetivo de conservação de uma entidade distinta. Entretanto, pode também haver a manipulação da consciência identitária por uma ideologia dominante quando a busca da identidade é compreendida como um desejo separatista. Como explica o antropólogo, em razão da discriminação racial, no discurso da negritude há uma referência retórica aos valores culturais negros ou a tentativa de recuperá-los, pelo menos simbolicamente. Munanga (2009) também defende que seria viável situar e colocar a questão da negritude dentro do movimento histórico, apontando os seus lugares de emergência e seus contextos de desenvolvimento. Historicamente, a negritude corresponde a uma reação à agressão racial branca, porém não é possível considerar que exista o chamado racismo reverso, pois seria necessário que o movimento negro estivesse em busca de supremacia, quando na realidade luta por condições de igualdade.

Para Munanga (2009), entre os problemas específicos da identidade negra está, entre outros, a alienação do seu corpo, de sua cor, de sua cultura, de sua história e, 
consequentemente, a sua "inferiorização" e baixa autoestima; além da falta de conscientização histórica e política etc. A busca por uma identidade funciona como uma terapia do grupo negro, em que é possível se despojar do complexo de inferioridade e se colocar em pé de igualdade com os outros oprimidos, o que é uma condição preliminar para uma luta coletiva. O antropólogo defende que a recuperação da identidade começa pela aceitação dos atributos físicos de sua negritude antes de atingir atributos complementares, pois o corpo constitui a sede material de todos os aspectos da identidade.

Os discursos engendrados fazem parte de uma cadeia de significados que interagem se interpõem mutuamente. Cada construção simbólica relaciona-se em algum grau com outros significantes enunciados em condições próprias de determinado contexto histórico. A enunciação de pessoas negras no contexto da luta por políticas afirmativas, principalmente em torno dos direitos básicos referentes à educação e à segurança pública, juntamente com a valorização da Cultura Afro-brasileira, materializa a luta por liberdade e autonomia. Para Bakhtin e Volóchinov (1997, p. 121, grifo dos autores), “o centro organizador de toda enunciação, de toda expressão, não é interior, mas exterior: está situado no meio social que envolve o indivíduo." A enunciação, enquanto tal, é um legítimo produto da interação social, quer se trate de um ato de fala determinado pela situação imediata ou pelo contexto mais amplo que constitui o arranjo das condições de vida de uma determinada comunidade linguística. A elaboração estilística da enunciação é de natureza sociológica, como a própria cadeia verbal que reduz, em última análise, a realidade da língua ao social. Os filósofos descrevem que cada elo dessa cadeia é social, assim como toda a dinâmica da sua evolução, e não pode ser deduzida enquanto expressão do mundo interior do locutor. Assim, toda palavra é ideológica e todo uso da língua está ligado à evolução ideológica, de forma que o conteúdo ideológico não pode ser deduzido do psiquismo individual. A abordagem deve partir do problema do diálogo, para uma melhor compreensão do fenômeno da interação verbal. Nesse sentido, Bakhtin e Volóchinov (1997, p. 123) definem que "a interação verbal constitui assim a realidade fundamental da língua", a partir de Otto Dietrich, para quem a função central da linguagem não é a expressão, mas a comunicação, e o par locutor-ouvinte constitui a condição necessária da linguagem.

Conforme Bakhtin (1997), o processo da comunicação verbal é complexo, envolvendo uma cadeia de enunciados numa dinâmica que determina uma atividade mediante aspectos que a inserem numa dada realidade:

De fato, o ouvinte que recebe e compreende a significação (linguística) de um discurso adota simultaneamente, para com este discurso, uma atitude responsiva 
ativa: ele concorda ou discorda (total ou parcialmente), completa, adapta, aprontase para executar etc., e esta atitude do ouvinte está em elaboração constante durante todo o processo de audição e de compreensão desde o início do discurso, às vezes já nas primeiras palavras emitidas pelo locutor. A compreensão de uma fala viva, de um enunciado vivo é sempre acompanhada de uma atitude responsiva ativa (conquanto o grau dessa atividade seja muito variável); toda compreensão é prenhe de resposta e, de uma forma ou de outra, forçosamente a produz: o ouvinte torna-se o locutor. A compreensão passiva das significações do discurso ouvido é apenas o elemento abstrato de um fato real que é o todo constituído pela compreensão responsiva ativa e que se materializa no ato real da resposta fônica subsequente. [...] cedo ou tarde, o que foi ouvido e compreendido de modo ativo encontrará um eco no discurso ou no comportamento subsequente do ouvinte. (BAKHTIN, 1997, p. 290, grifos do autor).

Nessa perspectiva, o filósofo define o enunciado como a "unidade real da comunicação verbal", estritamente delimitado pela alternância dos sujeitos falantes, e que termina por uma transferência da palavra ao outro. A fala existe somente na forma concreta dos enunciados de um indivíduo - do sujeito de um discurso-fala. O discurso se molda sempre à forma do enunciado que pertence a um sujeito falante, e quaisquer que sejam o volume, o conteúdo, a composição, os enunciados sempre possuem características estruturais que lhes são comuns, assim como fronteiras claramente delimitadas por cada ato responsivo.

Para Bakhtin (1997), a experiência verbal individual toma forma e evolui sob o efeito da interação contínua e permanente com os enunciados do outro. Trata-se de uma experiência que pode ser definida como um processo de assimilação, mais ou menos criativo, das palavras do outro, e não das palavras da língua. Os enunciados estão repletos de palavras dos outros, caracterizadas, em graus variáveis, pela alteridade ou pela assimilação por um emprego consciente e decalcado. As palavras dos outros introduzem a expressividade, o tom valorativo assimilado, reestruturado e modificado. Assim, a expressividade de um enunciado é sempre uma resposta onde se manifesta não somente a relação do locutor com o objeto do enunciado, mas também a relação do locutor com os enunciados dos outros. Esse processo é definido como ressonância dialógica.

A complexidade da fala de uma pessoa negra, no contexto estruturado pelo racismo, é moldada e absorve a discriminação e o preconceito contra si. A negritude engajada e a ideologia antirracista constituem um ente preparado para resistir e introduzir um novo tom apreciativo de contestação que constituirá uma resposta que possa repercutir no âmbito políticocultural. De acordo com Bakhtin (1997), a relação dialógica é marcada por uma profunda originalidade e que não pode ser reduzida a uma relação de ordem lógica, linguística, psicológica ou mecânica ou, ainda, a uma relação de ordem natural. Segundo o filósofo:

Não obstante, a relação dialógica não coincide de modo algum com a relação existente entre as réplicas de um diálogo real, por ser mais extensa, mais variada e mais complexa. Dois enunciados, separados um do outro no espaço e no tempo 
e que nada sabem um do outro, revelam-se em relação dialógica mediante uma confrontação do sentido, desde que haja alguma convergência do sentido (ainda que seja algo insignificante em comum no tema, no ponto de vista etc.). [...] Também não convém compreender a relação dialógica de modo simplista e unívoco e resumi-lo a um procedimento de refutação, de controvérsia, de discussão, de discordância. (BAKHTIN, 1997, p. 354).

Com isso, Bakhtin destaca o seu caráter de transformação. Resistir na linguagem, ocupando um lugar de fala, opera como parte do processo natural da construção de subjetividades e deve ocorrer mediante um ato de consciência dos fatores que determinam o horizonte histórico. A arquitetura instituída a partir da opressão da população negra a alijou da sua capacidade de se articular em torno da própria liberdade, mesmo após a Abolição. O comportamento de indivíduos negros foi afetado pelas condições sociopolíticas e econômicas, estabelecendo uma configuração conflitante com a demanda natural por espaço nas trocas simbólicas. A repressão imposta, inclusive por força policial, visa o silenciamento e a objetificação da/o oprimida/o, garantindo a dominação também no campo da linguagem, produzindo sujeitos sem lugar de fala e desmoralizados quanto à sua capacidade cognitiva. Nesse sentido, Kilomba (2019) aborda a chamada máscara do silenciamento, composta por um pedaço de metal fixado no interior da boca do sujeito negro. Era utilizada durante o período colonial para evitar que escravizadas/os comessem durante o trabalho nas plantações, fazendo parte também de uma política de silenciamento e tortura. A psicóloga descreve que, no âmbito do racismo, a boca corresponde ao órgão da opressão por excelência, e uma metáfora para a posse. Para justificar o controle brutal, o colonizador projeta no oprimido os seus vícios, fazendo-se de vítima em relação à/ao Outra/o, em termos psicanalíticos. Dessa forma, o opressor atribui a sua branquitude o status de honra e virtude, fantasiando também uma inimizade e os aspectos relacionados ao inconsciente coletivo que compõe a negritude como que pré-programada para a alienação, a decepção e o trauma psíquico. Kilomba (2019) define ainda que o racismo separa violentamente a/o oprimida/o de qualquer identidade que ela/ele realmente possui, sentenciando um grande trauma causado pelo seu silenciamento compulsório. A repressão de pessoas negras opera como uma forma de calar e negar as verdades que assombram a branquitude. Na dialética da comunicação, aqueles que são ouvidos são aqueles que "pertencem".

Moreira (2019), por seu turno, salienta que pessoas brancas não tratam pessoas negras de forma arbitrária por pura animosidade, mas em função do interesse na reprodução de sentidos culturais responsáveis pela sua afirmação como a única representação possível de agentes sociais competentes. A convicção de superioridade racial é o produto direto da transformação dos membros do grupo racial dominante como referência cultural, como referência 
estética, de superioridade moral, de superioridade intelectual, de superioridade sexual e de superioridade de classe. Nesse sentido, há a reiteração de que a raça não corresponde a um simples parâmetro de classificação biológica, mas a uma identidade social que posiciona os indivíduos dentro das relações hierárquicas existentes numa sociedade. Como explica Moreira (2019), a branquitude está relacionada aos interesses materiais das pessoas brancas e à violência porque motiva membros do grupo racial dominante a propagarem estereótipos que reproduzem a ideia de uma inferioridade essencial da negritude. A branquitude inscreve-se como uma propriedade estrutural das práticas sociais, porque determina o funcionamento das instituições e também das representações culturais.

Ramificado em todas as instituições da sociedade, o racismo é disseminado como uma prática da vida cotidiana. Seja de forma violenta, seja com humor, injúrias raciais são enunciadas com a total naturalidade. Segundo Bakhtin e Volóchinov (1997), quando a atividade mental, ou o conteúdo a exprimir, se realiza sob a forma de uma enunciação, ou objetivação externa, a orientação social à qual ela se submente adquire maior complexidade devido à exigência de adaptação ao contexto social imediato do ato de fala, e principalmente, aos interlocutores concretos. Os filósofos definem como ideologia do cotidiano a totalidade da atividade mental centrada sobre a vida cotidiana, assim como a expressão que a ela se liga, para distingui-las dos sistemas ideológicos constituídos, tais como a arte, a moral, o direito etc. A ideologia do cotidiano constitui o domínio da palavra interior e exterior desordenada e não fixada num sistema, que acompanha cada ato ou gesto e cada um dos estados de consciência. Bakhtin e Volóchinov (1997) afirmam que os sistemas ideológicos constituídos da moral social, da ciência, da arte e da religião cristalizam-se a partir da ideologia do cotidiano, exercendo por sua vez sobre esta, em retorno, uma forte influência que fixa o tom a essa ideologia. Os produtos ideológicos constituídos conservam um elo orgânico com a ideologia do cotidiano, pois se alimentam da sua avaliação crítica - a única razão de ser de toda produção simbólica.

De acordo com Bakhtin e Volóchinov (1997), os níveis superiores da ideologia do cotidiano que estão em contato direto com os sistemas ideológicos são substanciais e têm um caráter de responsabilidade e criatividade. São capazes de repercutir as mudanças da infraestrutura socioeconômica rápida e distintamente. Antes de invadir a arena da ideologia oficial constituída, assim que surgem, as novas forças sociais encontram sua primeira expressão e sua elaboração ideológica nesses níveis superiores da linguagem. Porém, os filósofos salientam que por mais revolucionárias que sejam essas correntes da ideologia do cotidiano, 
submetem-se à influência dos sistemas ideológicos estabelecidos, assimilando parcialmente as formas, práticas e abordagens ideológicas neles acumulados.

O antirracismo tem por demanda desnaturalizar a branquitude e as injustiças dela decorrentes, atuando na conscientização do uso da linguagem e, assim, reinscreve a negritude na trama social. Porém, o racismo é algo cristalizado, tematiza e serve de adubo para toda forma de expressão, no sentido de que, como afirma Moreira (2019), os estereótipos derrogatórios expressam a constituição dos lugares que os diversos grupos sociais devem ocupar, as suas supostas características, os limites da sua participação na estrutura política, a valoração cultural que podem almejar e, ainda, as oportunidades materiais às quais podem ter acesso. Enraizado no cotidiano e popularizado pela mídia, o racismo recreativo é uma política cultural característica de uma sociedade que formulou a transcendência racial como narrativa específica sobre as relações étnico-raciais. Moreira (2019) explica que pessoas brancas utilizam o humor para expressar a sua hostilidade e ainda assim afirmar que não são racistas. Esse projeto de dominação racial expressa a aversão que brancos sentem em relação à negritude, mas permite que figurem também como pessoas comprometidas com a igualdade. Assim, o caráter aversivo e o caráter simbólico do racismo recreativo operam paralelamente para referendar uma ordem política que cria mecanismos culturais e legais para impedir que haja mobilização política em torno da questão racial.

É necessário observar que os estereótipos descritivos e prescritivos expressos em piadas racistas são o produto de percepções que naturalizaram a condição inferior da negritude na sociedade, segundo Moreira (2019), para quem o racismo recreativo contribui na reprodução da hegemonia branca ao permitir que a dinâmica da assimetria de status cultural e de status material seja encoberta pela ideia de que o humor racista possui alguma natureza benigna. Essa política cultural preserva as narrativas sociais baseadas na noção de neutralidade racial - o elemento mantenedor de uma imagem positiva dos membros do grupo racial dominante que praticam os crimes de injúria e de racismo. De fato, o racismo recreativo deve ser compreendido como um projeto de dominação racial que opera de acordo com premissas específicas da cultura pública brasileira que, embora esteja baseado na noção de inferioridade moral do povo preto, está associado a um aspecto da doutrina racial brasileira que procura mitigar a relevância dessa prática social - a ideia de cordialidade essencial existente no Brasil.

O humor racista permite que membros do grupo racial dominante obtenham uma compensação de caráter narcisista. Complementando os mecanismos do racismo recreativo, Moreira (2019) analisa que há a perpetuação da falsa representação da irrelevância do racismo ao classificar piadas derrogatórias como atos que não expressam desprezo ou 
condescendência. Assim, esse comportamento propaga o elemento-chave da ideologia brasileira da democracia racial. Trata-se de uma narrativa cultural que tem sido historicamente empregada para dificultar a afirmação da raça como uma categoria socialmente relevante, permitindo que os indivíduos responsáveis pela propagação do racismo recreativo pensem que estão isentos da culpa pelo conteúdo de suas falas porque apenas reproduzem o que circula na sociedade.

Nessa sequência, Moreira (2019) afirma que as falsas generalizações da inferioridade da negritude embasam cognições sociais, formas de conhecimento compartilhado por certos segmentos a partir dos quais eles passam a atuar afirmando o senso de superioridade da branquitude. Todavia, o caráter aversivo do racismo com teor humorístico difere das expressões tradicionais de racismo baseadas na defesa aberta da superioridade branca. Corresponde a um projeto racial que assume a forma de uma violência simbólica, o que dificulta a criação de um sentimento de pertencimento social dos injuriados, comprometendo a sua reputação social, o que serve para legitimar as formas de exclusão. Ainda, legitima a prática e o riso do humor racista, além de reafirmar as representações derrogatórias de pessoas negras - a satisfação psicológica obtida ao reproduzir piadas racistas. Para Moreira (2019), portanto, a reprodução de estereótipos negativos valida a interação étnico-racial baseada na premissa de uma integração subordinada, com o propósito de referendar posições hierárquicas assimétricas e naturalizadas. O racismo recreativo está baseado nas noções de inferiorização social e de antipatia social. A primeira decorre dos sistemas de opressão, baseada na noção de que as/os negras/os são moral, intelectual, sexual e esteticamente inferiores a brancos. O racismo recreativo também está centrado na noção de antipatia racial, uma vez que as expressões cômicas de racismo expressam desprezo. Finalmente, Moreira (2019) observa que o racismo recreativo cria obstáculos significativos para a proteção legal de minorias raciais porque agentes públicos e privados coadunam na reprodução de uma narrativa que almeja encobrir a natureza estruturalmente racista das instituições brasileiras. É importante que as minorias raciais não internalizem e reproduzam também esses mecanismos.

A comunicação verbal é articulada segundo os parâmetros da ideologia do cotidiano que influencia a produção dos variados gêneros discursivos, na subjetividade de cada falante, e na compreensão de cada ouvinte. O tema ideológico, a materialidade metafórica do contexto histórico-linguístico, inscreve-se como uma possibilidade dominante da semântica dos discursos e que, obedecendo à dinâmica dialética da linguagem, é permeado por novas ideologias mediante signos reatualizados no embate entre os diversos grupos sociais. A língua portuguesa falada no Brasil, infelizmente e apesar da contribuição africana na sua formação, 
é permeada por sentidos pejorativos no uso de palavras que descrevem a negritude, a cultura e as tradições afro-brasileiras. Qual é a credibilidade de intelectuais negras e negros na construção e movimentação dos saberes acerca da negritude e de paradigmas epistemológicos como um todo? É possível que, numa perspectiva democrática, a conscientização acerca da violência e dos apagamentos perpetrados contra o povo preto seja o tema que contextualiza e baliza as relações étnico-raciais, substituindo a branquitude? Tudo depende das práticas sociais cotidianas, especialmente as linguísticas, que, intrinsicamente ligadas à forma com a qual são engendrados consensos reverberados no tecido social, constituem-se como políticas. Nesse contexto, devem ser agenciadas práticas antirracistas, produzindo inversões nos padrões estabelecidos e com a finalidade de subverter a branquitude. Assim, a negritude tem como atributo reconstruir e valorizar uma memória.

George Floyd, homem negro, foi detido e assassinado por dois policiais, em 25 de maio de 2020, na cidade de Minneapolis. Esse fato ocorrido nos Estados Unidos gerou uma onda de protestos contra o racismo e a violência policial em diversos países, inclusive no Brasil. O policial Derek Chauvin se ajoelhou sobre o pescoço de Floyd por quase nove minutos, enquanto a vítima implorava por sua vida. A abordagem ocorreu mediante a acusação de uma compra com uma nota falsa no valor de US\$20.00. Floyd já havia sido baleado numa abordagem policial anterior. Encadeou-se um protesto articulado a partir do enunciado Black lives matter², traduzido para "Vidas negras importam" no Brasil. A comoção engendrada entre os atores antirracistas inseriu uma valência semântica na sua luta, gerando enunciados responsivos que se baseiam numa resistência e que se inscrevem como "Todas as vidas importam" ou "Vidas brancas também importam". Essa comoção a partir do racismo, ancorada na ideologia dominante, não se ateve ao desperdício de vidas que ocorrem frequentemente. Antes, buscou silenciar, negar e perpetuar a dominância do seu grupo, afastando a compreensão do contexto em que se deu o movimento ativista internacional contra o genocídio provocado pelas forças do Estado. Uma mulher negra de 51 anos de idade teve o seu pescoço pisoteado por um policial, na cidade de São Paulo, no dia 30 de maio de 2020, chegando a desmaiar. Também foi agredida com socos no peito, chutes e puxões de cabelo, por tentar ajudar um amigo que apanhava de um policial na porta do seu estabelecimento. Assim, ilustramos o embate ideológico sob a dinâmica dialética na linguagem, reforçando a importância de enunciados de protesto em defesa das vidas negras.

\footnotetext{
${ }^{2}$ O movimento ativista internacional teve início em 2013 com o uso da hashtag \#BlacklivesMatter nas mídias sociais. O protesto foi causado pela absolvição do segurança responsável pela morte do adolescente afro-americano Trayvon Martin.
} 


\title{
Considerações finais
}

O povo preto ainda é açoitado e privado de sua cidadania, mediante opressões físicas e simbólicas. O racismo marca a ferro cada afro-brasileira e cada afro-brasileiro desde a sua infância, resultando num adoecimento psíquico. Constituindo-se como um anti-tema, a negritude é articulada na luta antirracista para materializar os direitos constituídos em lei ao longo da história, aliada a políticas afirmativas e ao engajamento artístico-cultural. Compreender o processo de racialização na formação da sociedade brasileira, enquanto um "Estado democrático", relacionado à instituição da branquitude como um parâmetro para o desfrute de privilégios e a permissão para desumanizar, permite a construção de uma visão crítica, desde que as reflexões sejam isentas do complexo sígnico que hierarquiza os indivíduos pela cor da sua pele. É necessário descolonizar-se, indignar-se com a opressão perpetrada contra todas as minorias étnico-raciais e políticas. O mito da democracia racial pode ser entendido como a base da hipocrisia brasileira.

\section{RACISM, ANTI-RACISM AND WHITENESS: THE SIGNS AND THE THEME IN DIALOGI- CAL RESONANCE IN THE IDEOLOGICAL FIGHTING}

\begin{abstract}
Mad Nigger", "naughty Black", "big lips" and "Bombril's hair" are some of the insults directed at black people. Racism structures and institutes the ordering of ethnic-racial relations through the theme of whiteness, from the colonial context to the present day. The ideologies around racialization reverberate as practices reproduced in the conditions of cultural production relations, impacting in different ways the political system that, a priori, excludes people of African descent from spaces of power and access to basic rights. The antithetical pairs in the struggle inscribed in the language around the significant "race" represent discourses disseminated by the transition from a dialectical dynamic, whose materiality also interferes in the consciousness and in the speech act of each individual.
\end{abstract}

KEYWORDS: Dialectic; Philosophy of Language; Ethnic-racial relations.

\section{REFERÊNCIAS}

ALMEIDA, Silvio. Luiz de. Racismo estrutural. São Paulo: Sueli Carneiro; Pólen, 2019.

BAKHTIN, Mikhail Mikhailovich. Estética da criação verbal. Tradução Maria Emsantina Galvão G. Pereira. 2. ed. São Paulo: Martins Fontes, 1997.

BAKHTIN, Mikhail Mikhailovich; VOLÓCHINOV, Valentin Nikoláievitch. Marxismo e filosofia da linguagem: problemas fundamentais do método sociológico na ciência da linguagem. Tradução Michel Lahud e Yara Frateschi Vieira. 8. ed. São Paulo: Hucitec, 1997.

BENTO, Maria Aparecida Silva. Branqueamento e branquitude no Brasil. In: CARONE, I.; BENTO, M. A. S. (Orgs.). Psicologia social do racismo: estudos sobre branquitude e branqueamento no Brasil. Petrópolis: Vozes, 2002, p. 25-58. Disponível em: http://www.media.ceert.org.br/portal-3/pdf/publicacoes/branqueamento-e-branquitude-no-brasil.pdf. Acesso em: 07 jun. 2020.

CARREIRA, Denise. O lugar dos sujeitos brancos na luta antirracista. SUR 28 - Revista Internacional de Direitos Humanos, v.15, n.28, p. 127 - 137, 2018. 
KILOMBA, Grada. A máscara. In: KILOMBA, G. Memórias da plantação: episódios de racismo cotidiano. Tradução Jess Oliveira. Rio de Janeiro: Editora Cobogó, 2019, p. 33-46. MOREIRA, Adilson. Racismo recreativo. São Paulo: Sueli Carneiro; Pólen, 2019.

MUNANGA, Kabengele. Negritude: usos e sentidos. 3. ed. São Paulo: Editora Autêntica, 2009.

RIBEIRO, Djamila. Pequeno manual antirracista. São Paulo: Companhia das Letras, 2019.

Recebido em: 28/09/2020.

Aprovado em: 26/01/2021. 